\title{
Vapor-Liquid Equilibrium at Several Experimental Conditions of the Binary Mixtures Methyl Lactate with n-Alkanols
}

\author{
Rubén Ezquerra, Alberto Latorre, Najla Ben Mahdoui and Carlos Lafuente*
}

Departamento de Química Física, Facultad de Ciencias, Universidad de Zaragoza, 50009 Zaragoza, Spain

\begin{abstract}
In this contribution the vapor-liquid equilibrium of the binary mixtures formed by methyl lactate and the first four lineal alkanols has been determined at constant pressure $(p=101.325 \mathrm{kPa})$ and at constant temperature $(T=$ $323.15 \mathrm{~K}$ ). The results have been adequately correlated with the Wilson equation. The obtained data have been satisfactorily checked for thermodynamic consistency using the van Ness method. Furthermore, we have applied the UNIFAC method to predict the vapor-liquid equilibrium and compared these predictions with the experimental results.
\end{abstract}

Keywords: n-Alkanols, Methyl lactate, Vapor-liquid equilibrium.

\section{INTRODUCTION}

Lactate esters have many applications in different fields; they are used as ingredients in chemical industry, as solvents for nitro and ethyl cellulose, oils, dyes, paints and in synthetic polymers. Moreover, lactate esters are also used as additives in biochemical, cosmetics and pharmaceuticals [1].

Among the methods for purification, the esterification of a lactate acid with a suitable alcohol and subsequent hydrolysis of the purified ester is widely accepted as highly efficient [2-5]. This complex process can be carried out by reactive distillation unit. The technology of reactive distillation offers a large number of advantages over the conventional sequential approach of reaction and separation [6]. For the correct design of a reactive distillation column, it is necessary to have knowledge of the phase equilibrium of the system to be separated according to the composition, temperature and pressure.

In this paper, the vapor-liquid equilibrium at isobaric $(p=101.325 \mathrm{kPa})$ and isothermal conditions $(T=$ $323.15 \mathrm{~K}$ ) of binary systems containing methyl lactate and a lineal alcohol (methanol, ethanol, 1-propanol and 1-butanol) has been measured over the whole composition range. The experimental data were correlated using the Wilson equation [7]. The obtained results have been checked for the thermodynamic consistency using the van Ness method [8, 9]. Finally, the UNIFAC group contribution method $[10,11]$ has been used to predict the vapor-liquid equilibrium of the systems studied here.

${ }^{*}$ Correspondence Address to this author at the Departamento de Química Física, Facultad de Ciencias, Universidad de Zaragoza, 50009 Zaragoza, Spain; Tel: +34976762295; Fax: +34976761202; E-mail: celadi@unizar.es
A survey of the literature shows that Sanz et al. [12] determined the isobaric vapor-liquid equilibrium for methanol + methyl lactate at three different pressures $(33.33,66.66$ and $101.33 \mathrm{kPa})$.

\section{EXPERIMENTAL}

The specifications (source, purity and water content) about the chemicals employed in this study can be found in Table 1. Due to the high purities of these compounds (at least 0.997 mass fraction) they were used without further purification. The water content of the liquids was measured using an automatic titrator Crison KF 1S-2B.

An all-glass ebulliometer (Labodest model) manufactured by Fischer was used in the isobaric and isothermal VLE measurements. The equilibrium temperature inside the apparatus was determined using a thermometer (model F25) from Automatic Systems Laboratories with an uncertainty of $0.02 \mathrm{~K}$ while the equilibrium pressure was measured with an uncertainty of $0.05 \mathrm{kPa}$ by means of a Digiquartz 735215A-102 pressure transducer.

In each measurement, the pressure or the temperature were fixed and the liquid mixture was kept at the boiling point for $30 \mathrm{~min}$. Then, samples of liquid and condensed vapor were analyzed by densitometry using a digital densimeter (DMA 5000 model) from Anton Paar, prior to this the corresponding densitycalibration curves were obtained [13]; the uncertainty in the determination of mole fraction compositions is 0.002 . The experimental equipment and operating procedures have been detailed in previous papers [14, 15].

The experimental normal boiling points and vapor pressures at $T=323.15 \mathrm{~K}$ of pure components, $T_{\mathrm{b}}$ and 
Table 1: Provenance, Purity and Water Content of the Compounds

\begin{tabular}{|c|c|c|c|c|}
\hline Compound & Source & Purity (mass fraction) & Analysis method & Water content / ppm \\
\hline \hline Methyl lactate & TCl & 0.997 & GC & 177 \\
\hline Methanol & Sigma-Aldrich & 0.998 & GC & 161 \\
\hline Ethanol & Acros & 0.998 & GC & 152 \\
\hline 1-Propanol & Sigma-Aldrich & 0.998 & GC & 197 \\
\hline 1-Butanol & Sigma-Aldrich & 0.999 & GC & 188 \\
\hline
\end{tabular}

Table 2: Normal Boiling Point, $T_{b}$, and Vapor Pressure at $T=323.15 \mathrm{~K}, p^{\circ}$, of the Pure Compounds and Comparison with Literature Data

\begin{tabular}{|c|c|c|c|c|}
\hline \multirow{2}{*}{ Compound } & \multicolumn{2}{|c|}{$T_{\mathrm{b}} / \mathrm{K}$} & \multicolumn{2}{|c|}{$p^{\circ} / \mathrm{kPa}$} \\
\hline & Exptl. & Lit. & Exptl. & Lit. \\
\hline Methyl lactate & 416.27 & $\begin{array}{l}417.95^{a} \\
416.93^{b}\end{array}$ & 2.400 & $2.399^{k}$ \\
\hline Methanol & 337.96 & $\begin{array}{c}337.92^{c} \\
337.9^{d}\end{array}$ & 55.735 & $55.566^{\prime}$ \\
\hline Ethanol & 351.50 & $\begin{array}{l}351.49^{e} \\
351.47^{f}\end{array}$ & 29.545 & $29.419^{\prime}$ \\
\hline 1-Propanol & 370.24 & $\begin{array}{l}370.26^{g} \\
370.20^{h}\end{array}$ & 12.185 & $12.132^{m}$ \\
\hline 1-Butanol & 390.71 & $\begin{array}{l}390.75^{i} \\
390.77^{j}\end{array}$ & 4.505 & $4.533^{n}$ \\
\hline
\end{tabular}

${ }^{a}[13] .{ }^{b}[17] .{ }^{c}[18] .{ }^{d}[19] .{ }^{e}$ [20]. ${ }^{f}[21] .{ }^{g}$ [22]. ${ }^{h}[23] .{ }^{i}[24] .{ }^{j}[25] .{ }^{k}[26] .{ }^{\prime}[27] .{ }^{m}[28] .{ }^{n}[29]$.

$p^{\circ}$, were determined using the same circulating apparatus used for mixtures measurement and they are listed in Table 2 along with some literature data [12, 16-28].

\section{RESULTS AND DISCUSSION}

The experimental data, $T-x_{1}-y_{1}$ or $p-x_{1}-y_{1}$, along with correlated activity coefficients can be found in the supplementary material. The corresponding $\left(T-x_{1}-y_{1}\right.$ or $\left.p-x_{1}-y_{1}\right)$ equilibrium diagrams can be seen in Figures 1 to 8 .

With respect to the comparison of our results at $p=$ $101.325 \mathrm{kPa}$ with previously published ones [12], the agreement is not very good, the average deviation in temperature is $0.99 \mathrm{~K}$ while the average deviation in vapor phase composition is 0.0075 .

The experimental vapor-liquid equilibrium data were correlated using the Wilson equation that correlates activity coefficients with the temperature, $T$, and the liquid phase mole fraction, $x_{i}$ :

$$
\ln \gamma_{i}=-\ln \left(\sum_{j} x_{j} \Lambda_{i j}\right)+1-\sum_{k} \frac{x_{k} \Lambda_{k i}}{\sum_{j} x_{j} \Lambda_{k j}}
$$

$$
\Lambda_{i j}=\frac{V_{j}^{\circ}}{V_{i}^{\circ}} \exp \left(-\frac{\lambda_{i j}-\lambda_{i i}}{R T}\right)
$$

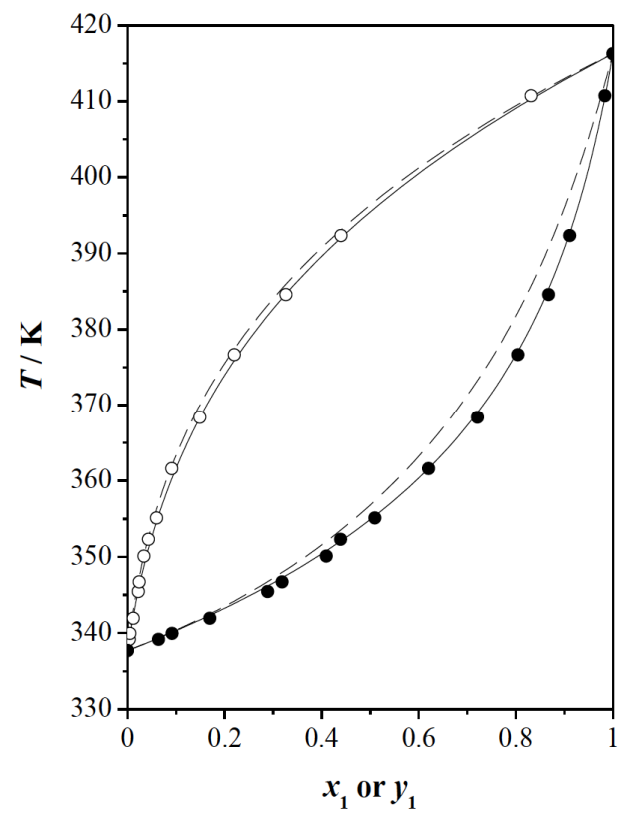

Figure 1: $T-x_{1}-y_{1}$ diagram for the binary mixture methyl lactate $(1)+$ methanol $(2):(\bigcirc, 0)$ experimental data at $p=$ $101.325 \mathrm{kPa}$; (-) Wilson correlation; (- - ) UNIFAC prediction. 


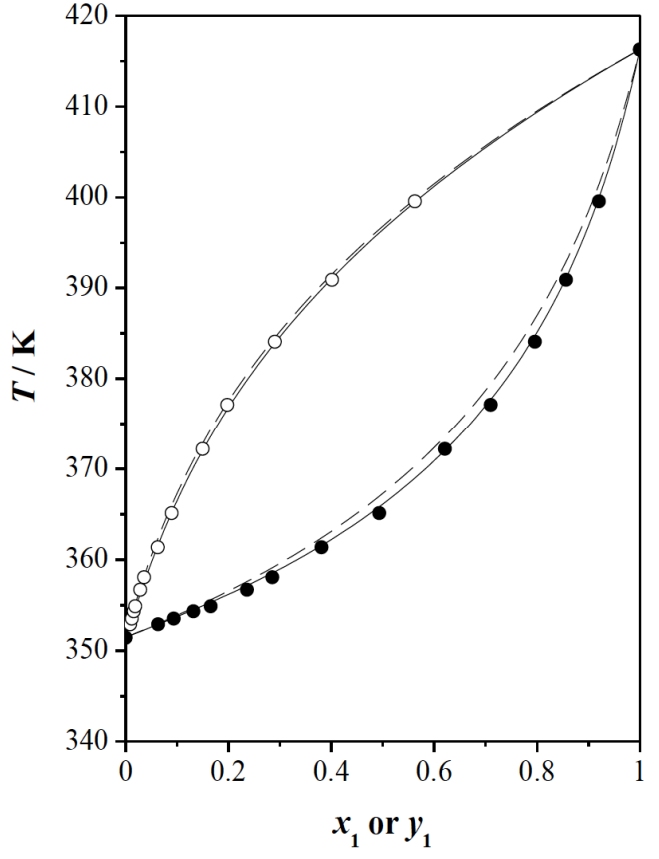

Figure 2: $T-x_{1}-y_{1}$ diagram for the binary mixture methyl lactate $(1)+$ ethanol $(2):(\bigcirc, 0)$ experimental data at $p=$ $101.325 \mathrm{kPa}$; (-) Wilson correlation; $(---)$ UNIFAC prediction.

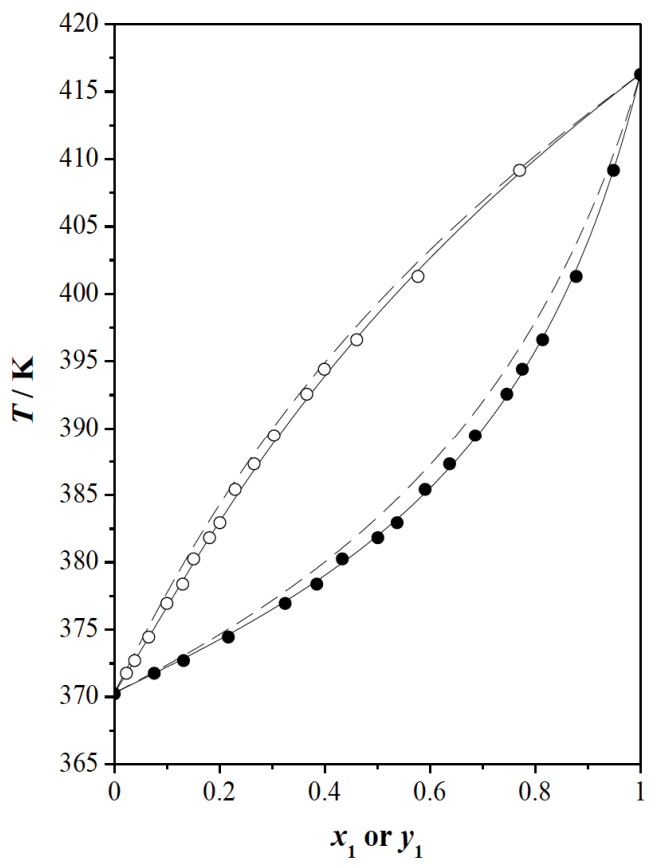

Figure 3: $T-x_{1}-y_{1}$ diagram for the binary mixture methyl lactate (1) + 1-propanol $(2):(\bigcirc, 0)$ experimental data at $p=$ $101.325 \mathrm{kPa} ;(-)$ Wilson correlation; $(---)$ UNIFAC prediction.

Where $\left(\lambda_{\mathrm{ij}}-\lambda_{\mathrm{ij}}\right)$ are the Wilson parameters, $V_{i}^{\circ}$ is the liquid molar volume of component $i$ at $T=298.15 \mathrm{~K}, R$ and $T$ are respectively the gas constant and the absolute temperature. The Wilson parameters have been obtained by minimizing the objective function in

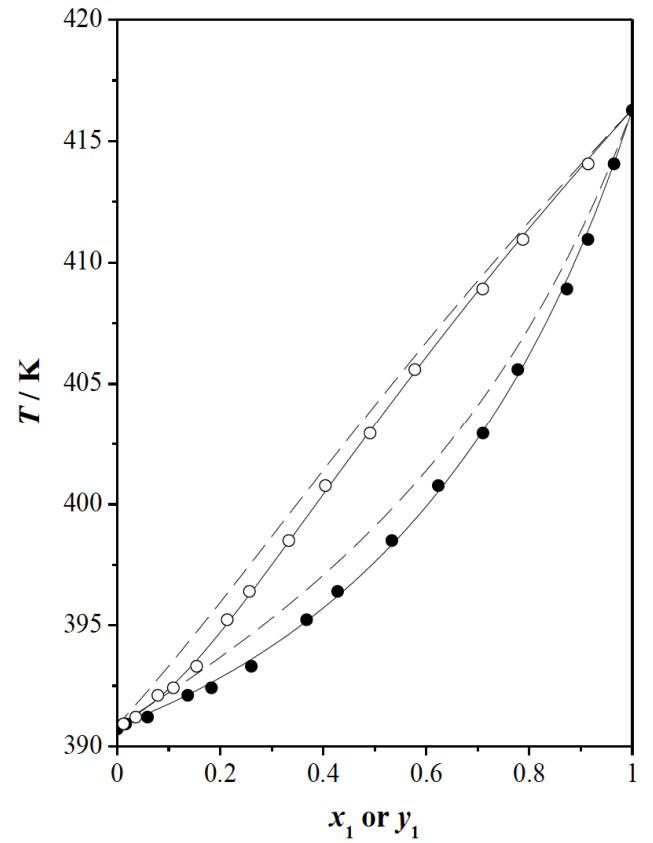

Figure 4: $T-x_{1}-y_{1}$ diagram for the binary mixture methyl lactate $(1)+1$-butanol $(2):(\bigcirc, 0)$ experimental data at $p=$ $101.325 \mathrm{kPa}$; (-) Wilson correlation; (- - -) UNIFAC prediction.

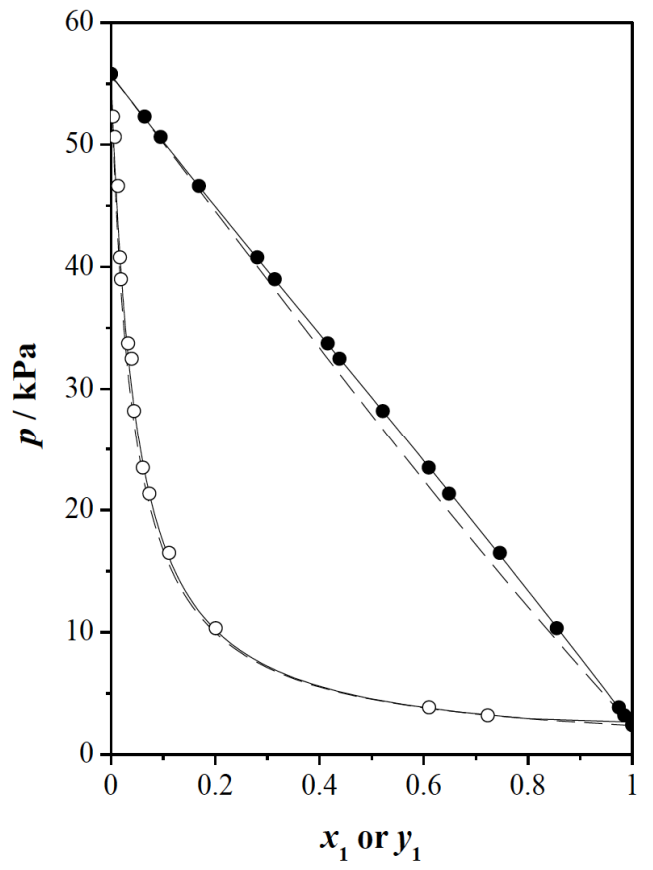

Figure 5: $p-x_{1}-y_{1}$ diagram for the binary mixture methyl lactate $(1)+$ methanol $(2):(O, 0)$ experimental data at $T=$ $323.15 \mathrm{~K}$; (-) Wilson correlation; (- - -) UNIFAC prediction.

terms of experimental and calculated pressures proposed by Silverman and Tassios [29]:

$F=\sum_{i=1}^{n}\left(\frac{p^{\exp }-p^{c a l}}{p^{\exp }}\right)_{i}^{2}$ 


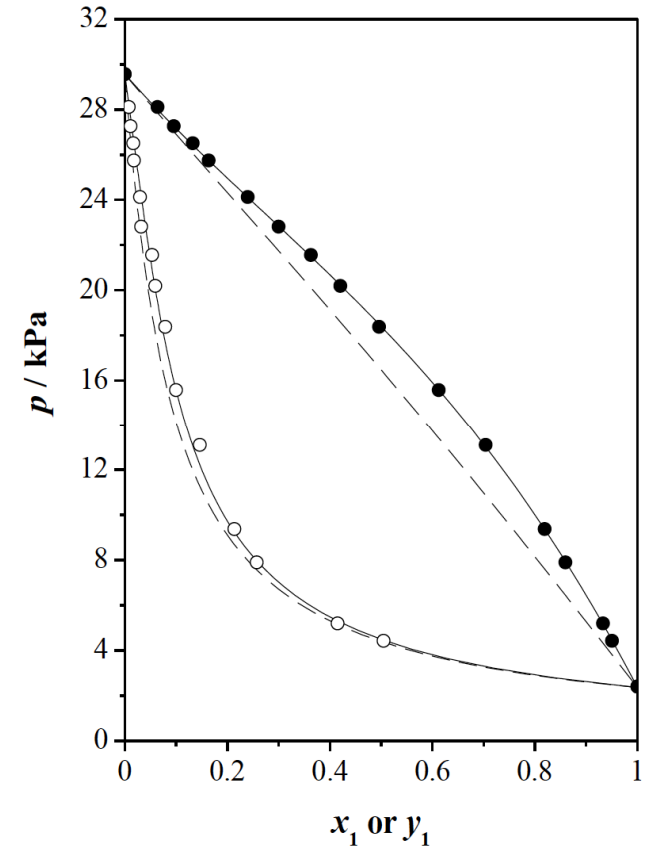

Figure 6: $p-x_{1}-y_{1}$ diagram for the binary mixture methyl lactate (1) + ethanol $(2):(\bigcirc, 0)$ experimental data at $T=$ $323.15 \mathrm{~K} ;(-)$ Wilson correlation; $(---)$ UNIFAC prediction.

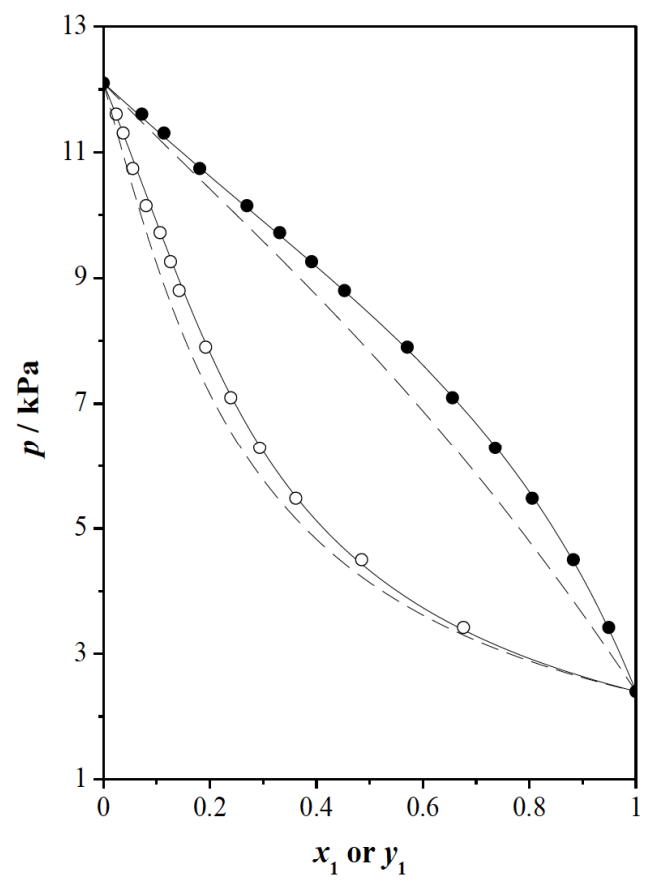

Figure 7: $p-x_{1}-y_{1}$ diagram for the binary mixture methyl lactate (1) + 1-propanol $(2):(\bigcirc, 0)$ experimental data at $T=$ $323.15 \mathrm{~K} ;(-)$ Wilson correlation; $(---)$ UNIFAC prediction.

For the computation of calculated pressures both the non-ideality of the vapor phase and the variation of the Gibbs function of the pure compounds with pressure have been taken into account, the calculated pressure is obtained from the following equations:

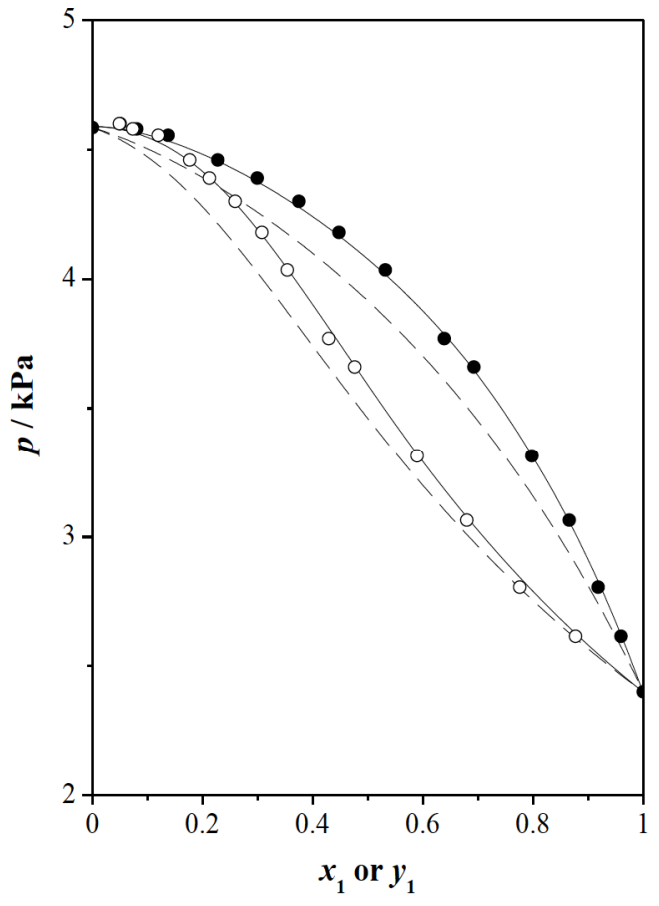

Figure 8: $p-x_{1}-y_{1}$ diagram for the binary mixture methyl lactate (1) + 1-propanol $(2):(\bigcirc, 0)$ experimental data at $T=$ $323.15 \mathrm{~K} ;(-)$ Wilson correlation; $(---)$ UNIFAC prediction.

$$
\begin{aligned}
& p^{c a l}=\sum_{i=1}^{2} x_{i} \gamma_{i} p_{i}^{\circ} \exp \left[\frac{\left(V_{i}^{\circ}-B_{i i}\right)\left(p-p_{i}^{\circ}\right)-\left(1-y_{i}\right)^{2} p \delta_{i j}}{R T}\right] \\
& \delta_{i j}=2 B_{i j}-B_{i i}-B_{j j}
\end{aligned}
$$

where $p$ and $p_{i}^{\circ}$ are respectively the total pressure and the vapor pressure of the pure compound $i, y_{i}$ is the vapor phase mole fraction, $V_{i}^{\circ}$ is the liquid molar volume of component $i$ at the equilibrium temperature and $B_{\mathrm{ii}}$ and $B_{\mathrm{ij}}$ are respectively the second virial coefficient of component $i$ and the cross second virial coefficient. The vapor pressures of the pure components as a function of the temperature were obtained by using the Antoine's equation, taking the constants from Riddick et al. [30] and Lomba et al. [25], the vapor pressure at $T=323.15 \mathrm{~K}$ were measured in our laboratory. The second virial coefficients were calculated using the Tsonopoulos' method [31, 32], and the saturated liquid molar volumes as a function of the temperature were estimated by means of the Rackett equation [33], these molar volumes at $T=323.15 \mathrm{~K}$ were experimentally determined.

Table 3 shows the estimated parameters of the Wilson equation at $p=101.325 \mathrm{kPa}$ or at $T=323.15 \mathrm{~K}$ for all the studied systems along with the corresponding average deviations in temperatures, $\Delta T$, 
Table 3: Parameters of the Wilson Equation, $\lambda_{\mathrm{ij}}-\lambda_{\mathrm{ii}}$, Average Deviation in Temperature, $\Delta T$, or Pressure, $\Delta p$, and Average Deviation in Vapor Phase Composition, $\Delta y$

\begin{tabular}{|c|c|c|c|c|c|}
\hline Experimentals conditions & $\lambda_{\mathrm{ij}}-\lambda_{\mathrm{ii}} / \mathrm{kJ} \cdot \mathrm{mol}^{-1}$ & $\lambda_{\mathrm{ij}}-\lambda_{\mathrm{ii}} / \mathrm{kJ} \cdot \mathrm{mol}^{-1}$ & $\Delta T / \mathrm{K}$ & $\Delta p / \mathrm{kPa}$ & $\Delta y$ \\
\hline \multicolumn{6}{|c|}{ Methyl lactate (1) + methanol (2) } \\
\hline$p=101.325 \mathrm{kPa}$ & -3262.46 & 3565.46 & 0.40 & & 0.0053 \\
\hline$T=323.15 \mathrm{~K}$ & -1592.40 & 1928.80 & & 0.073 & 0.0026 \\
\hline \multicolumn{6}{|c|}{ Methyl lactate (1) + ethanol (2) } \\
\hline$p=101.325 \mathrm{kPa}$ & 825.39 & 274.92 & 0.37 & & 0.0050 \\
\hline$T=323.15 \mathrm{~K}$ & 404.85 & 1291.09 & & 0.044 & 0.0043 \\
\hline \multicolumn{6}{|c|}{ Methyl lactate (1) + 1-propanol (2) } \\
\hline$p=101.325 \mathrm{kPa}$ & 2617.14 & -547.42 & 0.18 & & 0.0030 \\
\hline$T=323.15 \mathrm{~K}$ & 1029.93 & 636.65 & & 0.038 & 0.0044 \\
\hline \multicolumn{6}{|c|}{ Methyl lactate (1) + 1-butanol (2) } \\
\hline$p=101.325 \mathrm{kPa}$ & 993.09 & 114.15 & 0.24 & & 0.0030 \\
\hline$T=323.15 \mathrm{~K}$ & 1374.69 & 340.91 & & 0.025 & 0.0044 \\
\hline
\end{tabular}

or in pressures, $\Delta p$, and in vapor phase compositions, $\Delta y$, between the experimental results and the calculated ones. As can be seen in Table 3 , the correlation with the Wilson equation is quite good, the biggest deviation is shown by the system methyl lactate + methanol at $T=323.15 \mathrm{~K}$. The obtained data have been checked for thermodynamic consistency using the van Ness method [8], described by Fredenslund et al. [9], all the systems satisfied this test.

The systems deviate positively from Raoult's law, although these deviations are not high. Methyl lactate and alkanols have the possibility to form hydrogen bonds due to the presence of $\mathrm{OH}$ groups, these hydrogen bonds can be established with like or unlike molecules. The interactions between methyl lactate and an alkanol seems to be similar to those of the pure compounds [34], therefore the deviations from ideal behavior are small.

\section{UNIFAC PREDICTIONS}

The UNIFAC group contribution method is an effective tool for predicting the vapor-liquid equilibrium of multicomponent mixtures at isobaric or isothermal conditions. In this method, the liquid phase is considered as a mixture of functional groups. Thus, the vapor-liquid equilibrium of the system of interest can be calculated by using limited number of parameters describing the interactions between the structural groups [10]. In this work, we have employed the modified UNIFAC method to predict both isobaric and isothermal vapor-liquid equilibrium of the studied binary mixtures.

The graphical comparison between experimental and predicted results is shown in Figures 1-8. On the other hand, Table 4 displays the average deviations in temperature, $\Delta T$, at $p=101.325 \mathrm{kPa}$ or in pressure, $\Delta p$,

Table 4: UNIFAC Predictions: Average Deviations in Temperature, $\Delta T$, or Pressure, $\Delta p$, and in Vapor Phase Composition, $\Delta y$

\begin{tabular}{|c|c|c|c|}
\hline System & Experimentals conditions & $\Delta \boldsymbol{T} / \mathbf{K}$ & $\Delta \boldsymbol{p} / \mathbf{k P a}$ \\
\hline \hline Methyl lactate (1) + methanol (2) & $p=101.325 \mathrm{kPa}$ & 2.26 & 0.0179 \\
\cline { 2 - 4 } & $T=323.15 \mathrm{~K}$ & & 0.920 \\
\hline Methyl lactate (1) + ethanol (2) & $p=101.325 \mathrm{kPa}$ & 1.03 & 0.0075 \\
\cline { 2 - 4 } Methyl lactate (1)+ 1-propanol (2) & $T=323.15 \mathrm{~K}$ & & 0.0192 \\
\hline \multirow{2}{*}{ Methyl lactate (1) + 1-butanol (2) } & $p=101.325 \mathrm{kPa}$ & 1.14 & 0.0113 \\
\cline { 2 - 4 } & $T=323.15 \mathrm{~K}$ & & 0.0230 \\
\cline { 2 - 4 } & $p=101.325 \mathrm{kPa}$ & 1.01 & 0.0112 \\
\hline
\end{tabular}


at $T=323.15 \mathrm{~K}$ together with the deviation in vapor phase composition, $\Delta y$ between the experimental and predicted VLE data. These deviations indicate that for these mixtures the predictions are not very satisfactory. The overall average deviations in temperature and pressure are $\Delta T=1.36 \mathrm{~K}$ and $\Delta p=0.695 \mathrm{kPa}$, respectively. The worst results correspond to the systems: methyl lactate + methanol at $p=101.325 \mathrm{kPa}$ and methyl lactate + methanol at $T=323.15 \mathrm{~K}$.

\section{CONCLUSIONS}

In the present work, the vapor-liquid equilibrium for four binary mixtures: methyl lactate + methanol, methyl lactate + ethanol, methyl lactate +1 -propanol and methyl lactate + 1-butanol have been determined experimentally over the whole composition range at constant pressure $101.325 \mathrm{kPa}$ and at constant temperature $323.2 \mathrm{~K}$ using a Fischer-Labodest ebulliometer. The data were considered thermodynamically consistent by passing the Van Ness test.

The correlation of the measured data was performed using the Wilson activity coefficient model, the correlation is adequate.

Moreover, we have also used the UNIFAC method to calculate the the vapor-liquid equilibrium for our systems, these predictions are not quite satisfactory.

\section{SUPPLEMENTAL MATERIALS}

The supplemental materials can be downloaded from the journal website along with the article.

\section{REFERENCES}

[1] Clary JJ, Feron VJ, van Velthuijsen JA. Safety assessment of lactate esters. Regul Toxicol Pharmacol 1998; 27: 88-97. https://doi.org/10.1006/rtph.1997.1175

[2] Seo Y, Hong WH. Kinetics of esterification of lactic acid with methanol in the presence of cation exchange resin using a pseudo-homogeneous model. J Chem Eng Jpn 2000; 33: 128-133. https://doi.org/10.1252/jcej.33.128

[3] Choi JI, Hong WH, Chang HN. Reactions kinetics of lactic acid with methanol catalyzed by acid resins. Int J Chem Kinet 1996; 28: 37-41.

https://doi.org/10.1002/(SICI)1097-4601(1996)28:1<37::AIDKIN5>3.0.CO;2-N

[4] Troupe RA, Kobe KA. Kinetics of methanol-lactic acid reaction. Reaction with $44 \%$ technical acid. Ind Eng Chem 1950; 42: 1403-1409.

https://doi.org/10.1021/ie50487a040

[5] Troupe RA, Kobe KA. Kinetics of methanol-lactic acid reaction. Reaction with $85 \%$ technical acid. Ind Eng Chem 1950; 42: 801-810.

https://doi.org/10.1021/ie50485a020
[6] Taylor R, Krishna R. Modelling reactive distillation. Chem Eng Sci 2000; 55: 5183-5229.

https://doi.org/10.1016/S0009-2509(00)00120-2

[7] Wilson G. Vapor-liquid equilibrium. 11. New expression for excess free energy of mixing. J Am Chem Soc 1964; 86: 127-130.

https://doi.org/10.1021/ja01056a002

[8] Van Ness HC, Byer SM, Gibbs RE. Vapor-liquid equilibria. I. Appraisal of data reduction methods. AIChE J 1973; 19: 238244.

https://doi.org/10.1002/aic.690190206

[9] Fredenslund A, Gmehling J, Rasmussen P. Vapor-Liquid Equilibria Using UNIFAC. Amsterdam: Elsevier 1977.

[10] Fredenslund A, Jones RL, Prausnitz JM. Group-contribution estimation of activity-coefficients in nonideal liquid-mixtures. AIChE J 1975; 21: 1086-1099. https://doi.org/10.1002/aic.690210607

[11] Gmehling J, Li J, Schiller M. A modified UNIFAC model. 2. Present parameter matrix and results for different thermodynamic properties. Ind Eng Chem Res 1993; 32 178-193. https://doi.org/10.1021/ie00013a024

[12] Sanz MT, Calvo B, Beltrán S, Cabezas JL. Vapor-liquid equilibria at $(33.33,66.66$, and 101.33$) \mathrm{kPa}$, and densities at $298.15 \mathrm{~K}$ for the system methanol + methyl lactate. J Chem Eng Data 2002; 47: 1003-1006. https://doi.org/10.1021/je025513v

[13] Sánchez J, Artigas H, Gascón I, Lafuente C. Thermodynamic behaviour of alkyl lactate - alkanol systems. J Chem Thermodyn; submitted for publication 2018.

[14] Antón V, Martín S, Lafuente C, Gascón I. Experimental and predicted vapour liquid equilibrium of the binary mixtures nheptane + chlorobutane isomers. Fluid Phase Equilib 2016; 409: $72-77$.

https://doi.org/10.1016/..fluid.2015.09.031

[15] Ben Mahdoui N, Artigas H, Lafuente C, Hichri M, Khattech I. Isobaric vapor-liquid equilibrium for the binary systems dimethyl disulfide + C1-C4 n-alkanol at 40.000 and 101.325 $\mathrm{kPa}$. J Chem Eng Data 2017; 62: 2037-2043. https://doi.org/10.1021/acs.jced.7b00078

[16] Lecat M. New binary azeotropes second list. Recl Trav Chim Pays-Bas 1926; 45: 620-627. https://doi.org/10.1002/recl.19260450902

[17] Dribika MM, Rashed IG, Biddulph MW. Vapor-liquid equilibria in the ternary system methyl alcohol - ethyl alcohol isopropyl alcohol at atmospheric pressure. J Chem Eng Data 1985; 30: 146-149 https://doi.org/10.1021/je00040a004

[18] Li Z, Li Q, Qiao R, Zhang K, Song X, Li C, Tang H, Liu Y Isobaric vapor-liquid equilibrium for methanol plus methyl ethyl ketone plus bis(trifluoromethylsulfonyl)i mide-based ionic liquids at $101.3 \mathrm{kPa}$. Fluid Phase Equilib 2016; 427: 9096.

\section{https://doi.org/10.1016/j.fluid.2016.06.048}

[19] Kato M, Tanaka H. Vapor-Liquid Equilibrium Determination with a flow-type ebulliometer for six binary systems made of alcohol and amine. J Chem Eng Data 1989; 34: 203-206. https://doi.org/10.1021/je00056a017

[20] Pienaar, C, Schwarz CE, Knoetze JH, Burger AJ. Vaporliquid-liquid equilibria measurements for the dehydration of ethanol, isopropanol, and n-propanol via azeotropic distillation using DIPE and isooctane as entrainers. J Chem Eng Data 2013; 58: 537-550. https://doi.org/10.1021/je300847v

[21] Hiaki T, Takahashi K, Tsuji T, Hongo M, Kojima K. Vaporliquid equilibria of ethanol $+2,2,4$-trimethylpentane at 333.15 $\mathrm{K}$ and 1-propanol + 2,2,4-trimethylpentane at $343.15 \mathrm{~K}$. J Chem Eng Data 1994; 39: 605-607. https://doi.org/10.1021/je00015a048 
[22] Reddy VK, Rambabu K, Devarajulu T, Krishnaiah A. Volume of mixing, speed of sound, and viscosity of methyl cellosolve with aliphatic alcohols at $308.15 \mathrm{~K}$. J Chem Eng Data 1995; 40: 124-127.

https://doi.org/10.1021/je00017a028

[23] Cabezas JL, Beltran S, Coca, J. Isobaric vapor-liquid equilibrium data for the binary systems 1,2- dimethoxyethane + alcohols. J Chem Eng Data 1991; 36: 184-188. https://doi.org/10.1021/je00002a013

[24] Gonzalez E, Ortega, J. Densities and isobaric vapor-liquid equilibria for the mixtures formed by four butyl esters and 1butanol. J Chem Eng Data 1996; 41: 53-58. https://doi.org/10.1021/je9501649

[25] Lomba L, Giner B, Zuriaga E, Gascón I, Lafuente C. Thermophysical properties of lactates. Thermochim Acta 2014; 575: 305-312. https://doi.org/10.1016/j.tca.2013.11.010

[26] Garriga R, Sánchez F, Pérez P, Gracia M. Vapour pressures at six temperatures between $278.15 \mathrm{~K}$ and $323.15 \mathrm{~K}$ and excess molar functions at $\mathrm{T}=298.15 \mathrm{~K}$ of (butanone + methanol or ethanol). J Chem Thermodyn 1996; 28: 567576. https://doi.org/10.1006/jcht.1996.0053

[27] Munday EB, Mullins JC, Edie DD. Vapor pressure data for toluene, 1-pentanol, 1-butanol, water, and 1-propanol and for the water and 1-propanol system from 273.15 to $323.15 \mathrm{~K}$. J Chem Eng Data 1980; 25: 191-194. https://doi.org/10.1021/je60086a006
[28] Grigoryan ZI, Kazoyan EA, Markaryan SA. Thermodynamics of liquid-vapor phase equilibrium in dimethyl sulfoxidealkanol systems in the range of 293.15-323.15 K. Russ J Phys Chem 2015; 89: 1790-1794. https://doi.org/10.1134/S0036024415100131

[29] Silverman N, Tassios DP. Prediction of multicomponent vapor liquid equilibrium with the Wilson equation - Effect of the minimization function and of the quality of binary data. Ind Eng Chem Process Des Dev 1984; 23: 586-589. https://doi.org/10.1021/i200026a030

[30] Riddick JA, Bunger WB, Sakano TK. Organic Solvents, Physical Properties and Methods of Purification (Techniques of Chemistry), $4^{\text {th }}$ ed. New York: Wiley-Interscience 1986.

[31] Tsonopoulos C. Empirical correlation of second virial coefficients. AIChE J 1974; 20: 263-272. https://doi.org/10.1002/aic.690200209

[32] Tsonopoulos C, Dymond JH. Second virial coefficients of normal alkanes, linear 1-alkanols (and water), alkyl ethers, and their mixtures. Fluid Phase Equilib 1997; 133: 11-34. https://doi.org/10.1016/S0378-3812(97)00058-7

[33] Rackett HG. Equation of state for saturated liquids. J Chem Eng Data 1970; 15: 514-517. https://doi.org/10.1021/je60047a012

[34] Resa JM, Cepeda EA, Goenaga JM, Ramos A, Aguirre S, Urbano C. Density, refractive index, speed of sound at 298.15 , and vapor-liquid equilibrium at $101.3 \mathrm{kPa}$ for binary mixtures of methanol + ethyl lactate and 1-propanol + ethyl lactate. J Chem Eng Data 2010; 55: 1017-1021. https://doi.org/10.1021/je900481e 